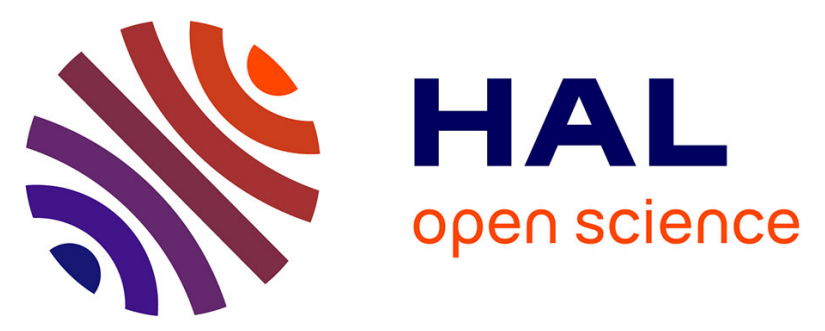

\title{
Visible light assisted oxidative coupling of benzylamines using heterostructured nanocomposite photocatalyst
}

Anurag Kumar, Abderrahmane Hamdi, Yannick Coffinier, Ahmed Addad, Pascal Roussel, Rabah Boukherroub, Suman L Jain

\section{- To cite this version:}

Anurag Kumar, Abderrahmane Hamdi, Yannick Coffinier, Ahmed Addad, Pascal Roussel, et al.. Visible light assisted oxidative coupling of benzylamines using heterostructured nanocomposite photocatalyst. Journal of Photochemistry and Photobiology A: Chemistry, 2018, 356, pp.457-463. 10.1016/j.jphotochem.2018.01.033 . hal-02321992

\section{HAL Id: hal-02321992 \\ https://hal.science/hal-02321992}

Submitted on 21 Oct 2019

HAL is a multi-disciplinary open access archive for the deposit and dissemination of scientific research documents, whether they are published or not. The documents may come from teaching and research institutions in France or abroad, or from public or private research centers.
L'archive ouverte pluridisciplinaire HAL, est destinée au dépôt et à la diffusion de documents scientifiques de niveau recherche, publiés ou non, émanant des établissements d'enseignement et de recherche français ou étrangers, des laboratoires publics ou privés. 


\section{Accepted Manuscript}

Title: Visible light assisted oxidative coupling of benzylamines using heterostructured nanocomposite photocatalyst

Authors: Anurag Kumar, Abderrahmane Hamdi, Yannick Coffinier, Ahmed Addad, Pascal Roussel, Rabah Boukherroub, Suman L. Jain

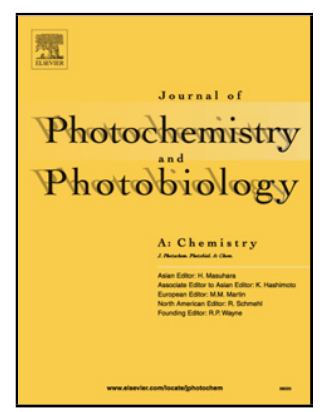

PII: S1010-6030(17)31742-2

DOI: $\quad$ https://doi.org/10.1016/j.jphotochem.2018.01.033

Reference: $\quad$ JPC 11121

To appear in: Journal of Photochemistry and Photobiology A: Chemistry

Received date: $\quad$ 27-11-2017

Revised date: $\quad$ 6-1-2018

Accepted date: $\quad 22-1-2018$

Please cite this article as: Anurag Kumar, Abderrahmane Hamdi, Yannick Coffinier, Ahmed Addad, Pascal Roussel, Rabah Boukherroub, Suman L.Jain, Visible light assisted oxidative coupling of benzylamines using heterostructured nanocomposite photocatalyst, Journal of Photochemistry and Photobiology A: Chemistry https://doi.org/10.1016/j.jphotochem.2018.01.033

This is a PDF file of an unedited manuscript that has been accepted for publication. As a service to our customers we are providing this early version of the manuscript. The manuscript will undergo copyediting, typesetting, and review of the resulting proof before it is published in its final form. Please note that during the production process errors may be discovered which could affect the content, and all legal disclaimers that apply to the journal pertain. 


\section{Visible light assisted oxidative coupling of benzylamines using heterostructured nanocomposite photocatalyst}

Anurag Kumar, ${ }^{1,2}$ Abderrahmane Hamdi, ${ }^{3}$ Yannick Coffinier, ${ }^{3}$ Ahmed Addad, ${ }^{4}$ Pascal Roussel, ${ }^{5}$ Rabah Boukherroub $^{3^{*}}$, Suman L. Jain ${ }^{1 *}$

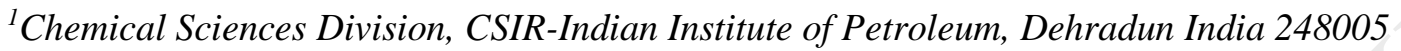

${ }^{2}$ Academy of Scientific and Industrial Research (AcSIR), New Delhi India 110001

${ }^{3}$ Univ. Lille, CNRS, Centrale Lille, ISEN, Univ. Valenciennes, UMR 8520 - IEMN, F-59000 Lille, France

${ }^{4}$ Univ. Lille, CNRS, UMR 8207 - UMET, F-59000 Lille, France

${ }^{5}$ Univ. Lille, CNRS, Centrale Lille, ENSCL, Univ. Artois, UMR 8181 - UCCS - Unité de Catalyse et Chimie du Solide, F-59000 Lille, France

"E-mail: suman@iip.res.in; rabah.boukherroub@iri.univ-lille1.fr

\section{Graphical Abstract}

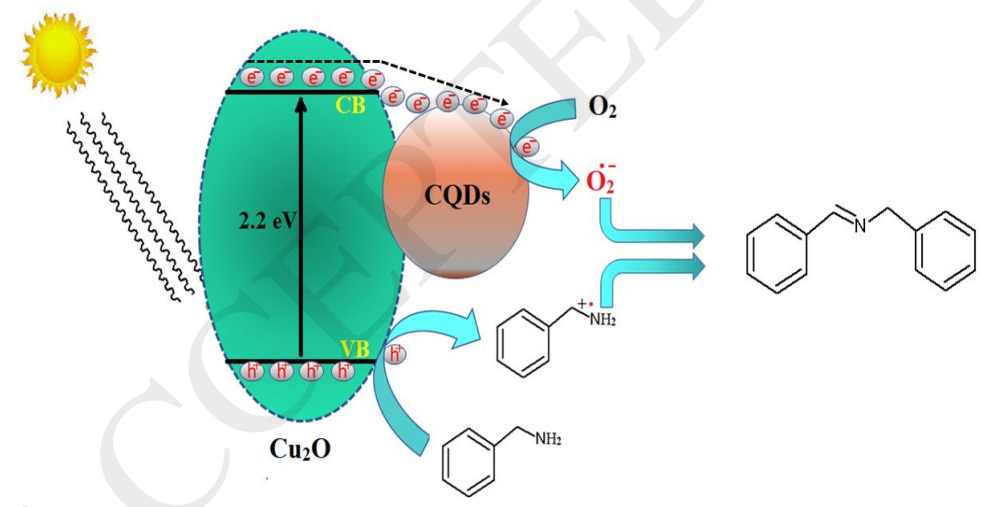




\title{
Highlights of the research
}

- Facile synthesis of hybrid nanocomposite consisting of copper (I) oxide and carbon quantum dots.

- Heterogeneous photocatalyst for organic transformation

- Visible light assisted oxidative coupling of benzyl amine

- A green, economical and efficient photochemical approach

- Higher activity and robustness of hybrid photocatalyst than neat $\mathrm{Cu}_{2} \mathrm{O}$ and CQDs.

- Facile recovery and efficient recycling of the photocatalyst.

\begin{abstract}
The present paper describes a simple and direct synthesis of heterostructured nanocomposite consisting of copper(I) oxide and carbon quantum dots $\left(\mathrm{Cu}_{2} \mathrm{O} / \mathrm{CQD}\right)$. The structure and composition of the photocatalyst were determined by X-ray diffraction (XRD), X-ray photoelectron spectroscopy (XPS), scanning electron microscopy (SEM), transmission electron microscopy (TEM), UV-Vis diffuse reflectance spectroscopy and Raman spectroscopy. The synthesized photocatalyst was used for coupling of benzylamines using molecular oxygen as oxidant and house hold white LED as light emitting source under mild reaction conditions. The developed photocatalyst exhibited excellent activity, robustness and efficient recycling without any significant loss in activity for several runs.
\end{abstract}

Keywords: Photocatalysis; oxidative coupling; quantum dots; hybrid catalyst; benzylamine. 


\subsection{Introduction}

Sunlight is a unique natural energy source which is inexpensive, nonpolluting and abundantly available. Hence, the replacement of high-energy synthetic processes with clean, cost effective and green photochemical approaches has become an area of tremendous importance in recent decades [1]. So far, many semiconductor photocatalysts have been reported for organic transformations [2]; however, less efficiency, limited visible light absorbance and poor conversion rates are certain drawbacks associated with these methodologies [3]. Copper(I) oxide $\left(\mathrm{Cu}_{2} \mathrm{O}\right)$ is a promising visible light active semiconductor which possesses some unique properties such as narrow band gap (2.2 eV), low cost, non-toxicity, better environmental acceptability and good adsorption of molecular oxygen [4]. Owing to these physical and chemical properties, $\mathrm{Cu}_{2} \mathrm{O}$ has extensively been investigated in solar conversion processes and catalysis [5]. Furthermore, the coupling of $\mathrm{Cu}_{2} \mathrm{O}$ with other semiconductors to form heterostructured composites is a promising approach for enhancing the charge separation as well as photo-activity [6]. In this regard, a number of heterostructured composites consisting of $\mathrm{Cu}_{2} \mathrm{O}$ and semiconductors like $\mathrm{TiO}_{2}, \mathrm{CdS}, \mathrm{ZnO}$ and $\mathrm{CuO}$ have been reported for numerous photocatalytic applications [7].

In the recent years, carbon quantum dots (CQD), novel nanosized carbon materials with less than $10 \mathrm{~nm}$, have gained significant interest in the area of catalytic and photocatalytic applications. Owing to their excellent optical and electronic properties including higher absorbance and superior charge transfer, these materials have widely used in photocatalytic applications [8]. In addition, low cost, non-toxicity, facile functionalization, good biocompatibility and chemical inertness make CQD as the material of choice in place of commonly known inorganic semiconductor and organic dye photocatalysts [9]. 
In recent years, photocatalytic oxidation processes using visible light irradiation are gaining considerable interest for the maximum utilization of solar energy as it consists of nearly $45 \%$ of the solar spectrum [10]. In addition, most of the photo-catalytic transformations occur under ambient conditions which are advantageous over thermocatalytic processes, which require higher reaction temperatures [11]. Among the various oxidation processes, oxidative coupling of amines to corresponding imines is an important chemical transformation in organic synthesis. These compounds have found wide applications as synthetic intermediates in the preparation of bioactive molecules of therapeutic interest [12]. Conventional oxidation methods involve the use of stoichiometric oxidants such as 2-iodoxybenzoic acid, N-test-butylphenylsulfinimidoyl chloride, which produce copious amounts of undesirable waste and are deterimental to the environment. Subsequently, catalytic methods using ruthenium based catalysts such as $\mathrm{RuCl}_{3}$, $\left[\mathrm{RuCl}_{2}\left(\mathrm{RCH}_{2} \mathrm{NH}_{2}\right)_{2}\left(\mathrm{PPh}_{3}\right)_{2}\right]$, ruthenium (II) porphyrin, ruthenium-hydroxyapatite, $\mathrm{Ru}_{2}(\mathrm{OAc})_{4} \mathrm{Cl}$ and $\mathrm{Ru} / \mathrm{Al}_{2} \mathrm{O}_{3}$ in conjunction with molecular oxygen as oxidant have been reported for this transformation [13]. However, very few reports are known on the photocatalytic oxidation of benzylic amines to the corresponding imines using $\mathrm{O}_{2}$ as an oxidant. In this context, $\mathrm{Su}$ and coworkers reported mesoporous graphite carbon nitride $\left(\mathrm{mpg}-\mathrm{C}_{3} \mathrm{~N}_{4}\right)$ for the oxidation of benzylic alcohols and amines with $\mathrm{O}_{2}$ under visible light [14]. Higher pressure $(0.5 \mathrm{MPa})$ and need of halogenated solvent (trifluorotoluene) make this methodology of limited applicability. Furukawa et al. [15] described niobium oxide/ $\mathrm{O}_{2}$ system for the photo-oxidation of amines. Apart from these semiconductor photocatalysts, recently, Berlicka et al. [16] investigated porphyrin or porphycene-mediated photo-oxidation of primary amines to $N$-benzylidene benzylamines in excellent conversion yields. Despite the excellent activity of these dyes under visible light, homogeneous nature and non-recyclability are the obvious drawbacks associated with this system. Hence, the development of heterogeneous photocatalyst along with the use of low cost 
metals under visible light irradiation is highly desired from both environmental and economic viewpoints. Raza et al. [17] studied oxidative coupling reactions of amines by photoactive $\mathrm{WS}_{2}$ nanosheets. More recently, Kumar et al. [18] reported an efficient semiconductor-metal complex hybrid photocatalyst, namely, graphitic carbon nitride $\left(\mathrm{g}-\mathrm{C}_{3} \mathrm{~N}_{4}\right)$ and iron (III) bipyridine complex for the oxidation of the benzylic amines with molecular oxygen under visible light irradiation. However, the multi-step synthesis of the hybrid photocatalyst makes the developed methodology of limited practical applicability.

In this paper, we report an efficient and simple visible light assisted heterostructured nanocomposite consisting of cuprous oxide $\left(\mathrm{Cu}_{2} \mathrm{O}\right)$, carbon quantum dots (CQD) i.e. $\mathrm{Cu}_{2} \mathrm{O} / \mathrm{CQD}$ catalyzed photo-oxidation of benzylamines using molecular oxygen as an oxidant to the corresponding imines under ambient conditions (Scheme 1).

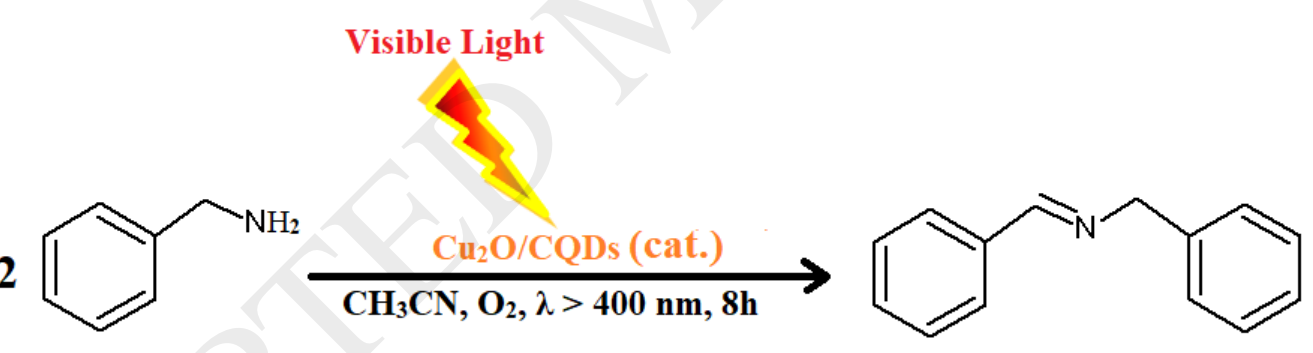

Scheme 1: Photo-oxidation of benzylamines.

\section{Experimental Section}

\subsection{Materials}

Fructose, sodium hydroxide $(\mathrm{NaOH})$, and copper perchlorate $\left(\mathrm{Cu}\left(\mathrm{ClO}_{4}\right)_{2}\right)$ were obtained from Sigma Aldrich (France) and used as received. 


\subsection{Techniques used}

SEM images were obtained using an electron microscope Hitachi S4700 equipped with a cold field emission emitter and two different detectors (high efficiency In-lens SE detector, EverhartThornley Secondary Electron Detector). The samples were prepared by casting $50 \mu \mathrm{L}$ aqueous of $\mathrm{Cu}_{2} \mathrm{O}-\mathrm{CQD}$ composite on a clean silicon wafer followed by drying in an oven at $80{ }^{\circ} \mathrm{C}$ to remove adsorbed water. Transmission electron microscopy (TEM) imaging was performed on a FEI Tecnai G2-F20 microscope operating at an accelerating voltage of $200 \mathrm{kV}$. Powder X-ray diffraction (XRD) patterns were collected on a Bruker D8 advance diffractometer $(\mathrm{Cu}-\mathrm{K} \alpha$ radiation, $1.54056 \AA$ ) with an applied voltage of $40 \mathrm{kV}$ and an anode current of $40 \mathrm{~mA}$ in the $2 \theta$ range of $10-80^{\circ}$. UV/Vis absorption spectra were recorded using a Perkin Elmer Lambda UV/Vis 950 spectrophotometer in quartz cuvettes with an optical path of $10 \mathrm{~mm}$. The wavelength range was $200-800 \mathrm{~nm}$. X-ray photoelectron spectroscopy (XPS) experiments were performed in a PHI 5000 VersaProbe - Scanning ESCA Microprobe (ULVAC-PHI, Japan/USA) instrument at a base pressure below $5 \times 10^{-9} \mathrm{mbar}$. Monochromatic AlKa radiation was used and the $\mathrm{X}$-ray beam, focused to a diameter of $100 \mu \mathrm{m}$, was scanned on a $250 \times 250 \mu \mathrm{m}$ surface, at an operating power of $25 \mathrm{~W}(15 \mathrm{kV})$. Photoelectron survey spectra were acquired using a hemispherical analyzer at pass energy of $117.4 \mathrm{eV}$ with $0.4 \mathrm{eV}$ energy step. Core-level spectra were acquired at pass energy of $23.5 \mathrm{eV}$ with $0.1 \mathrm{eV}$ energy step. All spectra were acquired at $90^{\circ}$ between $\mathrm{X}$-ray source and analyzer and with the use of low energy electrons and low energy argon ions for charge neutralization. After subtraction of the Shirley-type background, the core-level spectra were decomposed into their components with mixed Gaussian-Lorentzian (30:70) shape lines using the CasaXPS software. Quantification calculations were performed using sensitivity factors supplied by PHI. The sample was prepared by casting a concentrated aqueous solution of the material onto silicon substrate followed by drying at $100{ }^{\circ} \mathrm{C}$ for $1 \mathrm{~h}$. 


\subsection{Synthesis of carbon dots}

Carbon quantum dots (CQDs) were synthesized by a one-pot method at a relatively low reaction temperature [19]. In a typical procedure, fructose $(500 \mathrm{mM})$ and sodium hydroxide $(500 \mathrm{mM})$ were added to $20 \mathrm{~mL}$ water. The resulting solution was placed into a Teflon-lined stainless-steel autoclave and heated at $50{ }^{\circ} \mathrm{C}$ for $1 \mathrm{~h}$. The solution turned from a colorless into brown.

\subsection{Synthesis of $\mathrm{Cu}_{2} \mathrm{O} / \mathrm{CQDS}$}

Copper perchlorate $(1.35 \mathrm{~g})$ was dissolved in $10 \mathrm{~mL}$ of previously prepared CQDs solution and heated at $80{ }^{\circ} \mathrm{C}$ for $3 \mathrm{~h}$. The formed precipitate was separated by centrifugation, washed with water three times and annealed at $120{ }^{\circ} \mathrm{C}$ overnight [19]. For comparison, $\mathrm{Cu}_{2} \mathrm{O}$ was prepared by the same procedure using copper chloride and sodium hydroxide without adding fructose as mentioned above. The $\mathrm{Cu}$ content in the $\mathrm{Cu}_{2} \mathrm{O} / \mathrm{CQDs}$ was determined by ICP-AES which was found to be $38.04 \mathrm{wt} \%$ ( $2.9 \mathrm{mmol} \mathrm{Cu} / \mathrm{g}$ catalyst).

\subsection{Photocatalytic oxidative coupling of benzylamines}

All the photocatalytic experiments were carried out by using a 20 watt white cold LED light (Model No. HP-FL-20W-F-Hope LED Opto-Electric Co., Ltd, $\lambda>400 \mathrm{~nm}$ ) as a light source. In a typical experiment, benzylamine $(1 \mathrm{mmol})$ and photocatalyst $(25 \mathrm{mg})$ were mixed in acetonitrile $(10 \mathrm{~mL})$. The resulting mixture was irradiated with visible light with stirring for $8 \mathrm{~h}$ in the presence of molecular oxygen. The progress of the reaction was monitored by TLC. After completion of the reaction, the photocatalyst was separated by filtration and the obtained residue was concentrated under reduced pressure to obtain a crude product. The pure product was obtained via purification using column chromatography on silica gel by using ethyl acetate: hexane (9:1) as eluent. 


\subsection{Results and Discussion}

\subsection{Synthesis and characterization of photocatalyst}

The $\mathrm{Cu}_{2} \mathrm{O} / \mathrm{CQD}$ investigated in this work was prepared according to a previous protocol published by some of us [19]. The morphology of the synthesized $\mathrm{Cu}_{2} \mathrm{O} / \mathrm{CQD}$ nanocomposite was investigated by scanning electron microscopy (SEM) and transmission electron microscopy (TEM). SEM image of the synthesized nanocomposite as shown in Figure 1a revealed nanoparticles in the aggregated form.
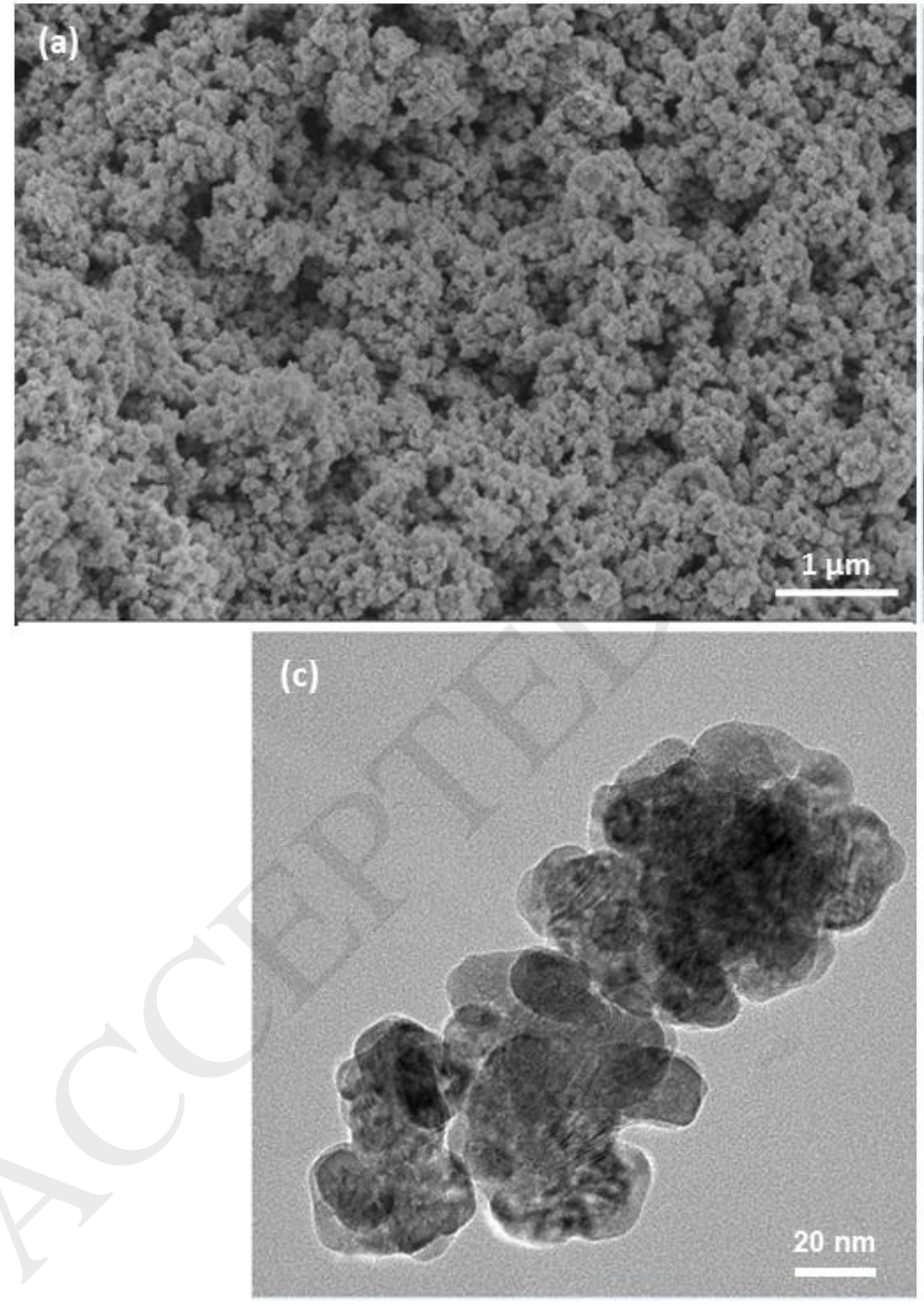
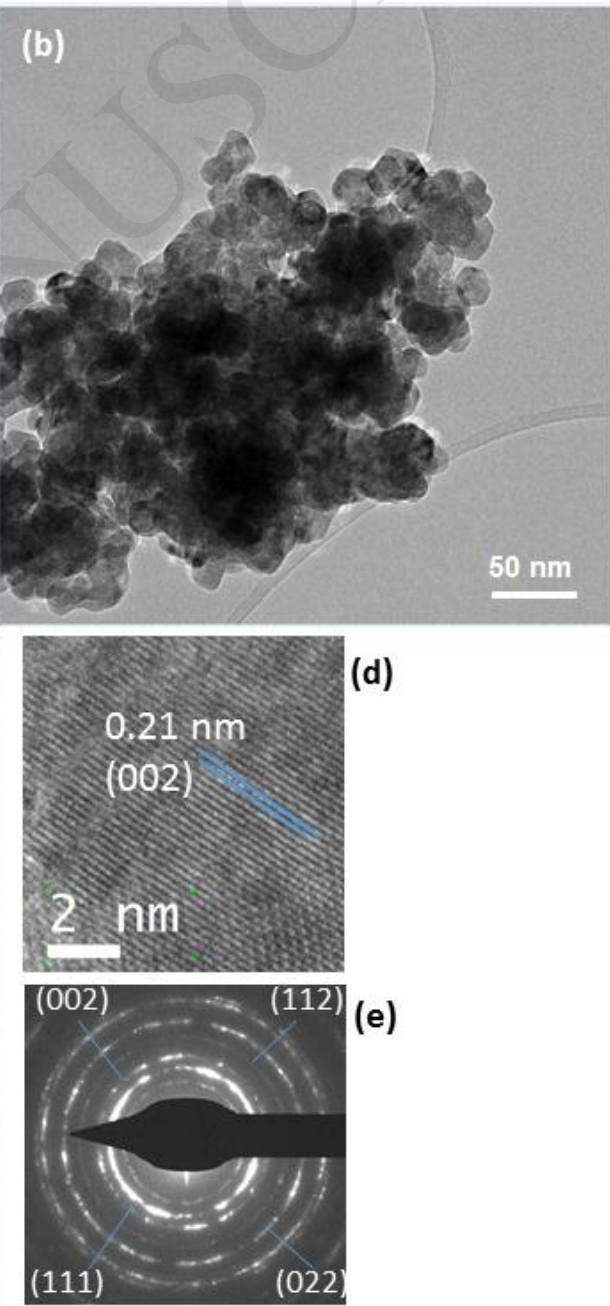

Figure 1. SEM (a), low (b) and high (c) resolution TEM images, (d) HR-TEM of a nanoparticle and (e) SAED of $\mathrm{Cu}_{2} \mathrm{O} / \mathrm{CQD}$. 
The TEM image of the prepared nanocomposite indicated $\mathrm{Cu}_{2} \mathrm{O}$ NPs of 20-30 nm in size (Fig. $1 \mathrm{~b}, \mathrm{c})$. In addition, in the HR-TEM image of a single $\mathrm{Cu}_{2} \mathrm{O}$ NP an interplanar distance of $0.21 \mathrm{~nm}$ between adjacent planes, related to the interplanar spacing of the (002) plane of $\mathrm{Cu}_{2} \mathrm{O}$ was observed (Fig. 1d). The appearance of five diffraction rings in the selected-area electron diffraction (SAED) pattern corresponding to the (022), (112), (002), (111), and (011) planes of $\mathrm{Cu}_{2} \mathrm{O}$ suggested the poly crystalline nature of the sample (Fig. 1e).

X-ray diffractogram of $\mathrm{Cu}_{2} \mathrm{O} / \mathrm{CQD}$ composite as shown in Figure 2 exhibited several reflections having at least two different crystalline phases of $\mathrm{Cu}$ (ICDD No. 65-9026) and $\mathrm{Cu}_{2} \mathrm{O}$ (ICDD No. 78-2076). The diffraction planes of the $\mathrm{Cu}$ phase observed at $43.2^{\circ}$ and $50.3^{\circ}$ were corresponded to the $\mathrm{Cu}(111)$ and $\mathrm{Cu}(200)$, respectively. The other diffraction peaks at $29.5^{\circ}, 36.5^{\circ}, 42.2^{\circ}$, $61.3^{\circ}$, and $73.7^{\circ}$ were related to the $\mathrm{Cu}_{2} \mathrm{O}$ (110), $\mathrm{Cu}_{2} \mathrm{O}$ (111), $\mathrm{Cu}_{2} \mathrm{O}$ (200), $\mathrm{Cu}_{2} \mathrm{O}$ (220) and $\mathrm{Cu}_{2} \mathrm{O}$ (311) crystalline planes, respectively. Indeed, very weak peaks of $\mathrm{Cu}$ appeared in the XRD pattern of $\mathrm{Cu}_{2} \mathrm{O} / \mathrm{CQD}$. However, the material is mostly $\mathrm{Cu}_{2} \mathrm{O}$ and also the chemical transformation is a photochemical process, the contribution of $\mathrm{Cu}$ is believed to be negligible. Hence we have denoted active photocatalyst as $\mathrm{Cu}_{2} \mathrm{O} / \mathrm{CQD}$. Additionally, a small peak at $\sim 22.8^{\circ}$ confirmed the presence of carbon from the CQD. These characterization results were found to be in good agreement with our previous reports on reduced graphene oxide modified with $\mathrm{Cu}_{2} \mathrm{O}$ [20], and $\mathrm{Cu}_{2} \mathrm{O}$ modified multi-walled carbon nanotube nanostructures [21] and CQD [22]. 


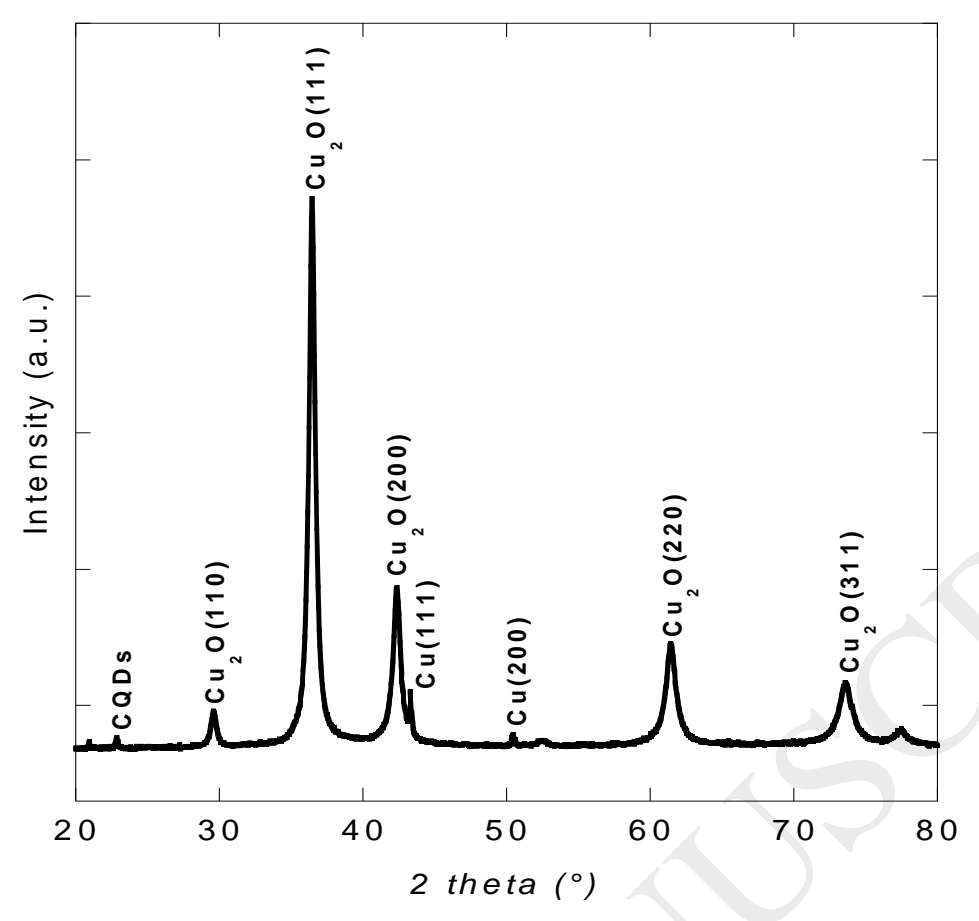

Figure 2. Powder X-ray diffraction pattern of $\mathrm{Cu}_{2} \mathrm{O} / \mathrm{CQD}$.

The UV-Vis spectra of nanocomposite $\mathrm{Cu}_{2} \mathrm{O} / \mathrm{CQD}$ and its components are shown in Figure. 3. The UV-vis absorption spectrum of CQDs in water revealed a main absorption peak at 293 and a shoulder at $340 \mathrm{~nm}$ attributed to the $\pi-\pi^{*}$ transition of the conjugated $\mathrm{C}=\mathrm{C}$ and the $\mathrm{n}-\pi^{*}$ transition of the $\mathrm{C}=\mathrm{O}$, respectively [19]. Interestingly, both $\mathrm{Cu}_{2} \mathrm{O}$ and $\mathrm{Cu}_{2} \mathrm{O} / \mathrm{CQD}$ absorb remarkably in the visible region, making these materials suitable for photocatalytic processes under visible light irradiation. The band gap of $\mathrm{Cu}_{2} \mathrm{O}$ was determined with the help of Tauc plot which was found to be $2.2 \mathrm{eV}$ (Fig. S3). According to the band gap, the absorption edge wavelength for $\mathrm{Cu}_{2} \mathrm{O}$ was estimated to be $563 \mathrm{~nm}$. 


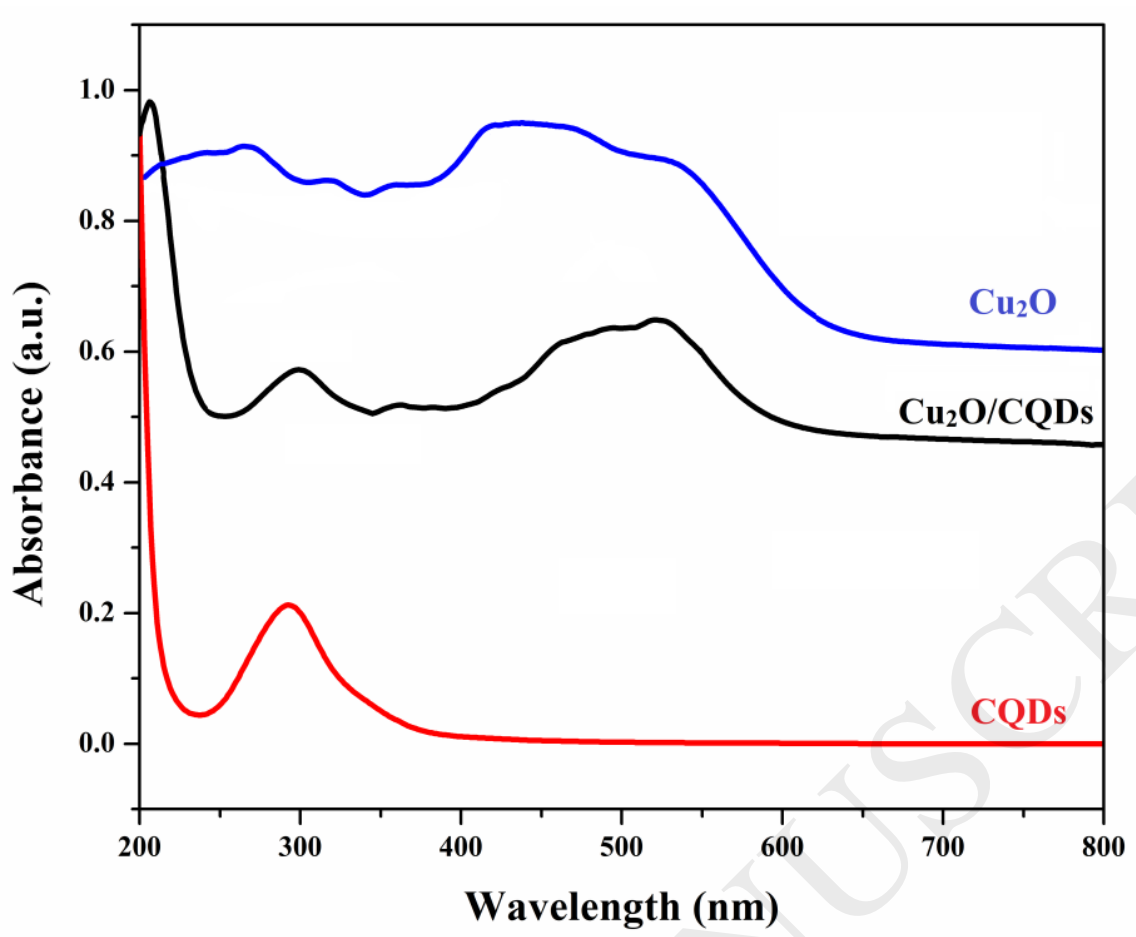

Figure 3. UV-Vis spectra of $\mathrm{CQD}, \mathrm{Cu}_{2} \mathrm{O} / \mathrm{CQD}$ and $\mathrm{Cu}_{2} \mathrm{O}$

The chemical composition of the synthesized nanocomposite was examined by X-ray photoelectron spectroscopy (XPS). In survey scan as shown in Figure S1, the appearance the corresponding peaks of all the desired elements such as $\mathrm{Cu}_{3 \mathrm{~s}}(75.0 \mathrm{eV}), \mathrm{Cu}_{3 \mathrm{p}}(122.5 \mathrm{eV}), \mathrm{C}_{1 \mathrm{~s}}$ $(285.0 \mathrm{eV}), \mathrm{O}_{1 \mathrm{~s}}(531.5 \mathrm{eV})$ and $\mathrm{Cu}_{2 \mathrm{p}}(532 \mathrm{eV})$ confirmed the successful synthesis of the material. The high-resolution XPS spectrum of $\mathrm{C}_{1 \mathrm{~s}}$ (Fig. 3) revealed the main peak at $\sim 285 \mathrm{eV}$ due to C-H, $\mathrm{C}-\mathrm{C}$ and $\mathrm{C}=\mathrm{C}$ bonds from the $\mathrm{CQD}$ along with two components at 286.2 and $288.6 \mathrm{eV}$ assigned to $\mathrm{C}-\mathrm{O}$ and $\mathrm{C}=\mathrm{O}$ bonds, respectively.

The XPS high-resolution spectrum of $\mathrm{Cu}_{2 \mathrm{p}}$ displayed two peaks at 932.5 and $952.4 \mathrm{eV}$ attributed to $\mathrm{Cu}_{2 \mathrm{p} 3 / 2}$ and $\mathrm{Cu}_{2 \mathrm{p} 1 / 2}$, respectively from $\mathrm{Cu}_{2} \mathrm{O}$ (Fig. 4). The XPS high-resolution spectrum of $\mathrm{O}_{1 \mathrm{~s}}$ exhibited peaks at 530.7 and $531.8 \mathrm{eV}$ respectively, due to the oxygen bonded to the carbon skeleton of the $\mathrm{CQD}$ and $\mathrm{Cu}-\mathrm{O}$ in $\mathrm{Cu}_{2} \mathrm{O}$ (Fig. S2). 

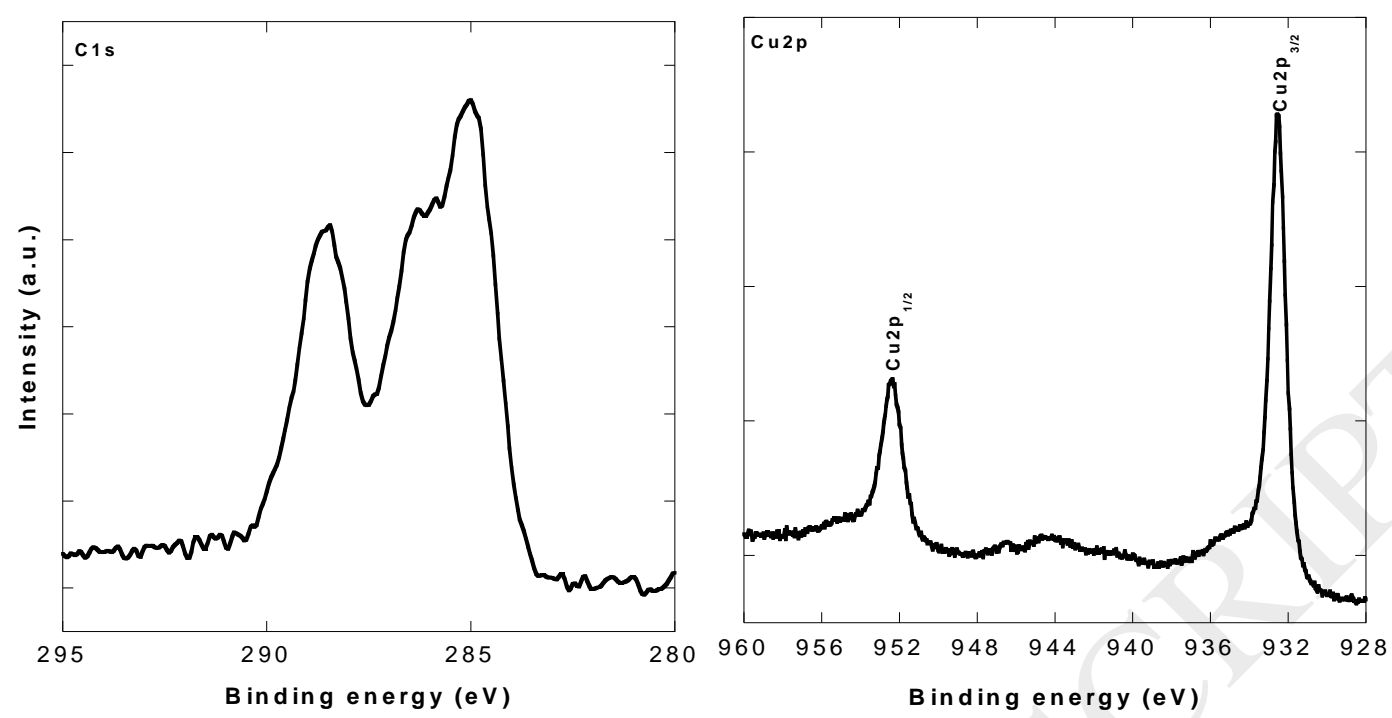

Figure 4. High-resolution XPS spectra of $\mathrm{C}_{1 \mathrm{~s}}$ and $\mathrm{Cu}_{2 \mathrm{p}}$ of $\mathrm{Cu}_{2} \mathrm{O} / \mathrm{CQD}$.

\subsection{Catalytic Activity}

The photocatalytic activity of the synthesized nanocomposite $\mathrm{Cu}_{2} \mathrm{O} / \mathrm{CQD}$ and its components were checked for the oxidation of benzylamine with $\mathrm{O}_{2}$ in acetonitrile solvent under visible light irradiation at ambient temperature and pressure conditions (Scheme 1). At first, optimization experiments using variable reaction parameters were performed and the results of these experiments are summarized in Table 1. In a blank reaction, no product was formed even in the prolonged time $(24 \mathrm{~h})$ in the absence of photocatalyst under otherwise identical conditions. (Table 1, entry 1). Similarly, in the absence of a visible light source, no reaction was occurred (Table 1 , entry 2), suggesting that the reaction was truly photocatalytic in nature. However, in the presence of visible light irradiation, the oxidation of benzylamine ( $1 \mathrm{mmol})$ using $25 \mathrm{mg} \mathrm{Cu} 2 \mathrm{O} / \mathrm{CQD}$ as a photocatalyst in $\mathrm{CH}_{3} \mathrm{CN}$ under an oxygen atmosphere at an ambient temperature $\left(25^{\circ} \mathrm{C}\right)$ and pressure (1 atm) afforded an almost quantitative yield of the corresponding imine (Table 1, entry 3). Furthermore, the use of neat $\mathrm{Cu}_{2} \mathrm{O}$ or $\mathrm{CQDs}$ as photocatalysts under identical conditions 
afforded only 12 and 30\% conversion, respectively (Table 1, entry 4-5). Furthermore, the effect of various solvents was studied to select the optimum reaction medium. Among the different solvents such as methanol, dimethylformamide, tetrahydrofuran, acetonitrile, and ethanol (Table 1, entries 3, 6-9) studied, acetonitrile $\left(\mathrm{CH}_{3} \mathrm{CN}\right)$ was found to be the best solvent for the reaction (Table 1, entry 3). Molecular oxygen played an essential role and in its absence (irradiation under nitrogen atmosphere), a negligible conversion was achieved (Table 1, entry 10). Although the reaction occurred efficiently at room temperature $\left(24{ }^{\circ} \mathrm{C}\right)$ at 1 atmospheric pressure, to check the effect of temperature, the reaction was performed at $50{ }^{\circ} \mathrm{C}$ under described conditions (Table 1, entry 3). A marginal enhancement in the conversion (97.5\%) was observed at higher temperature; therefore we selected room temperature as the optimum temperature for the reaction.

Table 1: Optimization of oxidative coupling of benzylamine with molecular oxygen under different reaction conditions ${ }^{[\mathrm{a}]}$

\begin{tabular}{|c|c|c|c|c|c|c|c|}
\hline Entry & $\begin{array}{c}\text { Visible } \\
\text { light }\end{array}$ & Solvent & Photocatalyst & $\begin{array}{l}\text { Time } \\
\text { (h) }\end{array}$ & $\begin{array}{l}\text { Conv. } \\
(\%)^{[\mathrm{b}]}\end{array}$ & $\mathrm{TON}^{[\mathrm{c}]}$ & $\begin{array}{l}\text { TOF } \\
\left(\mathrm{h}^{-1}\right)\end{array}$ \\
\hline 1 & Yes & $\mathrm{CH}_{3} \mathrm{CN}$ & No & 24 & - & - & - \\
\hline 2 & No & $\mathrm{CH}_{3} \mathrm{CN}$ & $\mathrm{Cu}_{2} \mathrm{O} / \mathrm{CQDs}$ & 24 & - & - & \\
\hline 3 & Yes & $\mathrm{CH}_{3} \mathrm{CN}$ & $\mathrm{Cu}_{2} \mathrm{O} / \mathrm{CQDs}$ & 8 & $\begin{array}{c}97, \\
97.5^{[\mathrm{d}]}\end{array}$ & $\begin{array}{l}13.8 \\
13.9\end{array}$ & $\begin{array}{l}1.7 \\
1.7\end{array}$ \\
\hline 4 & Yes & $\mathrm{CH}_{3} \mathrm{CN}$ & $\mathrm{Cu}_{2} \mathrm{O}$ & 10 & 15 & - & - \\
\hline 5 & Yes & $\mathrm{CH}_{3} \mathrm{CN}$ & CQDs & 10 & 30 & - & - \\
\hline 6 & Yes & $\mathrm{MeOH}$ & $\mathrm{Cu}_{2} \mathrm{O} / \mathrm{CQDs}$ & 10 & 74 & 10.6 & 1.1 \\
\hline 7 & Yes & DMF & $\mathrm{Cu}_{2} \mathrm{O} / \mathrm{CQDs}$ & 10 & 92 & 13.1 & 1.3 \\
\hline 8 & Yes & $\mathrm{THF}$ & $\mathrm{Cu}_{2} \mathrm{O} / \mathrm{CQDs}$ & 10 & 54 & 7.7 & 0.8 \\
\hline 9 & Yes & $\mathrm{EtOH}$ & $\mathrm{Cu}_{2} \mathrm{O} / \mathrm{CQDs}$ & 10 & 75 & 10.7 & 1.1 \\
\hline $10^{[\mathrm{d}]}$ & Yes & $\mathrm{CH}_{3} \mathrm{CN}$ & $\mathrm{Cu}_{2} \mathrm{O} / \mathrm{CQDs}$ & 8 & trace & - & - \\
\hline
\end{tabular}

[a] Reaction conditions: benzylamine (1 mmol), photocatalyst $(25 \mathrm{mg})$, solvent $(10 \mathrm{~mL})$, light source: white cold LED $\lambda>400 \mathrm{~nm}$, time: 8-24 h under oxygen balloon; Power at reaction vessel: $70 \mathrm{~W} / \mathrm{m}^{2}$; ${ }^{[b]}$ determined by GC-MS; ${ }^{[c]} \mathrm{TON}$ is defined as the amount of product formed to that of the active site $\mathrm{Cu}$ in the photocatalyst; ${ }^{[\mathrm{d}]}$ at $50{ }^{\circ} \mathrm{C}$ temeprature; ${ }^{[\mathrm{e}]}$ in the absence of molecular oxygen under $\mathrm{N}_{2}$ atmosphere. 
Furthermore, the reaction was generalized to variously substituted benzylamines under optimized reaction conditions using $\mathrm{Cu}_{2} \mathrm{O} / \mathrm{CQD} / \mathrm{O}_{2}$ system under visible light at room temperature. The results of these reactions are summarized in Table 2. All the substrates afforded corresponding imine products selectively without observing any by-product. Moreover, marginal substituent effect was observed and all the substrates containing either electron-releasing or withdrawing groups were smoothly and efficiently converted to the resultant $N$-benzylidene benzylamines in good to excellent yields (75-95\%). The slightly higher activity of the electron rich amines might be due to the easy formation of an intermediate imine. Furthermore, o-substituted benzylamine displayed slightly poor product yield as compared to the p-isomer, which is mainly due to the obvious reason of steric hindrance (Table 2, entry 4). Secondary benzylamine (dibenzylamine) also showed high reactivity and afforded moderate product yield (Table 2, entry 8). However, cyclohexylamine was not reacted under the described conditions (Table 2, entry 10). 
Table 2: $\mathrm{Cu}_{2} \mathrm{O} / \mathrm{CQD}$-catalyzed oxidative coupling of benzylamines ${ }^{[\mathrm{a}]}$

\begin{tabular}{|c|c|c|c|c|}
\hline Entry & Substrate & Product & $\begin{array}{l}\text { Conv. } \\
(\%)^{[b]}\end{array}$ & $\begin{array}{l}\text { Yield } \\
(\%)^{[c]}\end{array}$ \\
\hline 1 & & & 97 & 95 \\
\hline 2 & & & 97.5 & 95 \\
\hline 3 & & & 97 & 93 \\
\hline 4 & & & 91 & 88 \\
\hline 5 & & & 94 & 90 \\
\hline 6 & & & 94 & 91 \\
\hline 7 & & & 89 & 85 \\
\hline 8 & & & 90 & 86 \\
\hline 9 & & & 79 & 75 \\
\hline 10 & & - & - & - \\
\hline
\end{tabular}

${ }^{a}$ Reaction conditions: benzylamine $(1 \mathrm{mmol}), \mathrm{Cu}_{2} \mathrm{O} / \mathrm{CQD}(25 \mathrm{mg})$, acetonitrile $(10 \mathrm{~mL})$ under visible light irradiation with white cold LED $\lambda>400 \mathrm{~nm}$ for $8 \mathrm{~h}$; Power at reaction vessel: $70 \mathrm{~W} / \mathrm{m}^{2}$; ${ }^{\text {bdetermined by }}$ GC-MS; 'Isolated yield.

Further, to check the recyclability of the material, recycling experiments were performed by choosing benzylamine as a representative example. After completion of the reaction; the photocatalyst was separated by simple filtration, washed with acetonitrile, dried and reused in the subsequent experiments for six runs (Fig. 5). Almost similar conversion and product yield were obtained in all cases, suggesting that the synthesized photocatalyst was highly stable in nature. Furthermore, to ascertain the leaching of metal, selected filtrate samples of recycling 
experiments were subjected to ICP-AES analysis. No metal trace was detected in the solution phase, indicating no leaching had occurred and the reaction was truly heterogeneous in nature.

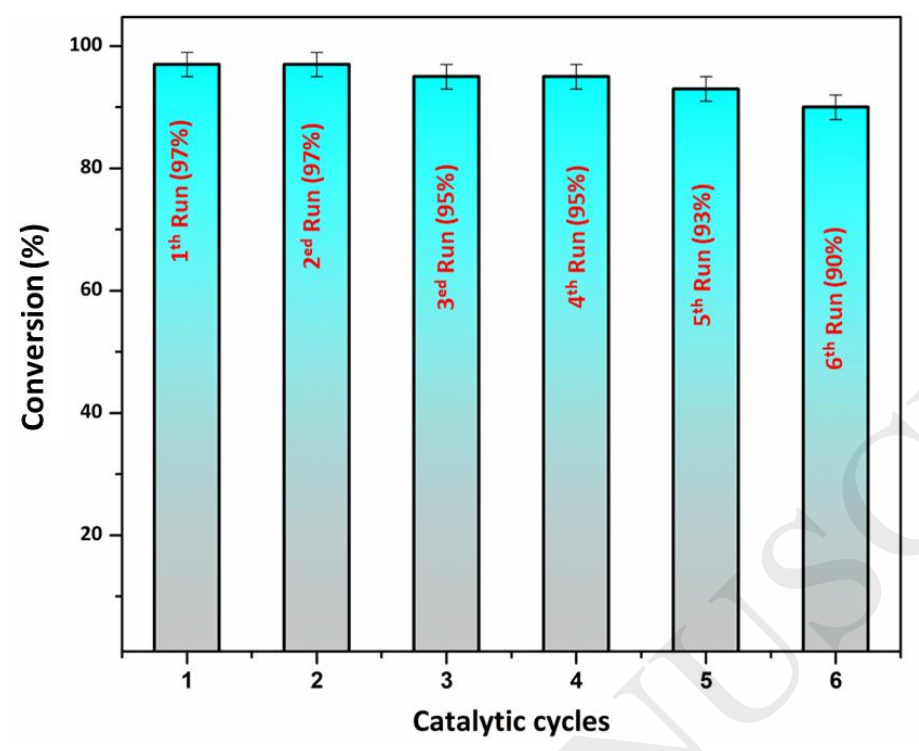

Figure 5. Results of recycling experiments.

Although, the exact mechanism of the reaction is not clear at this stage, based on our experimental findings and existing literature reports [17] a plausible mechanism of the reaction is depicted in Scheme 2. As shown in a controlled experiment that oxygen played a pivotal role and in its absence the reaction did not occur (Table 1, entry 10). It is believed that after absorbing the light, charge separation takes place in photocatalyst $\mathrm{Cu}_{2} \mathrm{O} / \mathrm{CQD}$. The photogenerated electrons were excited from the $\mathrm{VB}$ to the $\mathrm{CB}$ of $\mathrm{Cu}_{2} \mathrm{O}$. Subsequently the photo-generated electrons were transferred to CQD, which act as electron collector, transporter to provide better mobility and charge separation. Furthermore, molecular oxygen gets excited under light and converted to the singlet oxygen which can accept an electron from the conduction band of nanocomposite to give superoxide radical. To confirm the formation of superoxide radical, the reaction was performed by adding a common radical scavenger, i.e. $p$-benzoquinone (BQ). A significant decrease in the 
product yield was observed, which confirmed the formation of superoxide radical as an intermediate during the photo-oxidation reaction. In the subsequent step, benzylamine transferred an electron to the valence band of photocatalyst and converted to cation radical as shown in Scheme 2. In the final step, superoxide radical abstracts a hydrogen atom from the benzylic position of a benzylamine radical cation to produce benzylimine, which interacted with another benzylamine molecule to give the corresponding $N$-benzylidene benzylamine along with $\mathrm{H}_{2} \mathrm{O}_{2}$ as a by-product (Scheme 2).

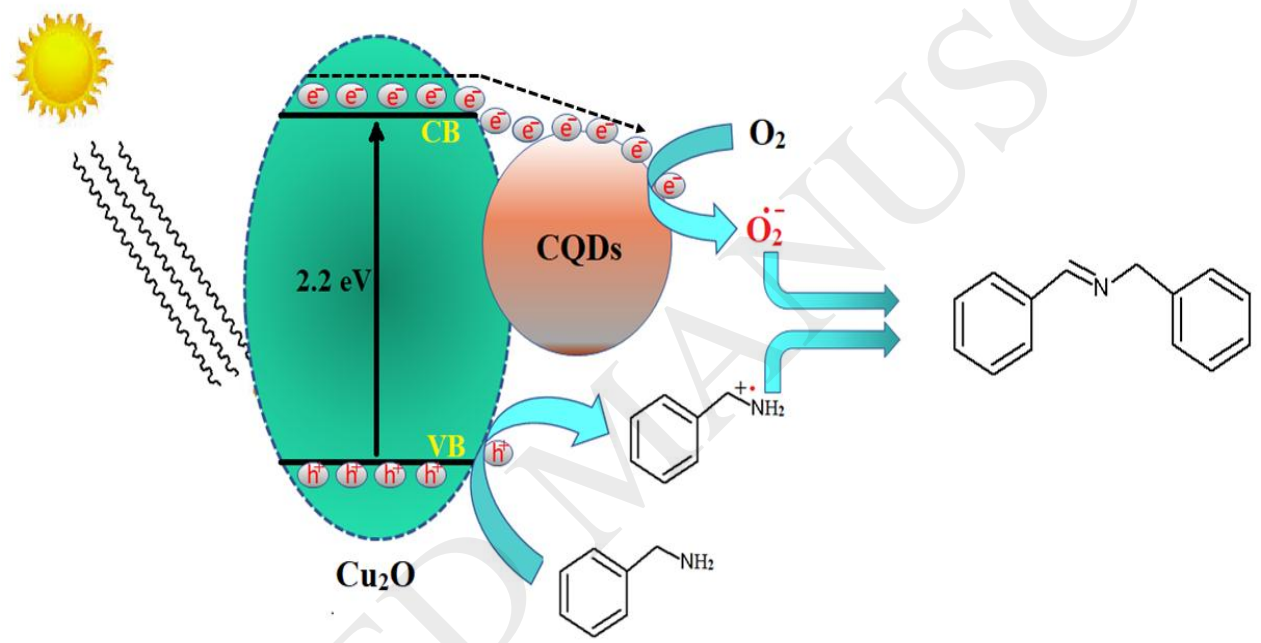

Scheme 2: Plausible mechanism of photocatalytic oxidative coupling of benzylamine in the presence of $\mathrm{Cu}_{2} \mathrm{O} / \mathrm{CQD}$.

\subsection{Formation of singlet oxygen in $\mathrm{Cu}_{2} \mathrm{O} / \mathrm{CQD}$ system under visible light irradiation}

The formation of singlet oxygen $\left({ }^{1} \mathrm{O}_{2}\right)$ during the photocatalytic oxidative coupling of benzylamine was investigated by adding sodium azide $\left(\mathrm{NaN}_{3}\right)$, a quencher of ${ }^{1} \mathrm{O}_{2}$. For this study, a comparison was made between the original photocatalytic experiment and that obtained after the addition of sodium azide $\left(\mathrm{NaN}_{3}\right)$ at different time intervals (Fig. 6). As shown in Fig. 6, the 
conversion of benzylamine using $\mathrm{Cu}_{2} \mathrm{O}$ /CQDs photocatalyst with oxygen under visible light irradiation was found to be $21,58,87.4$ and $97.5 \%$ after $2,4,6$ and $8 \mathrm{~h}$, respectively in the absence of $\mathrm{NaN}_{3}$. However, the conversion was reduced significantly, and maximum conversion reached only up to $12.5 \%$ after $8 \mathrm{~h}$ when $\mathrm{NaN}_{3}$ was added into the system. These experimental results confirmed the generation of singlet oxygen $\left({ }^{1} \mathrm{O}_{2}\right)$ in the photocatalytic system under visible light irradiation.

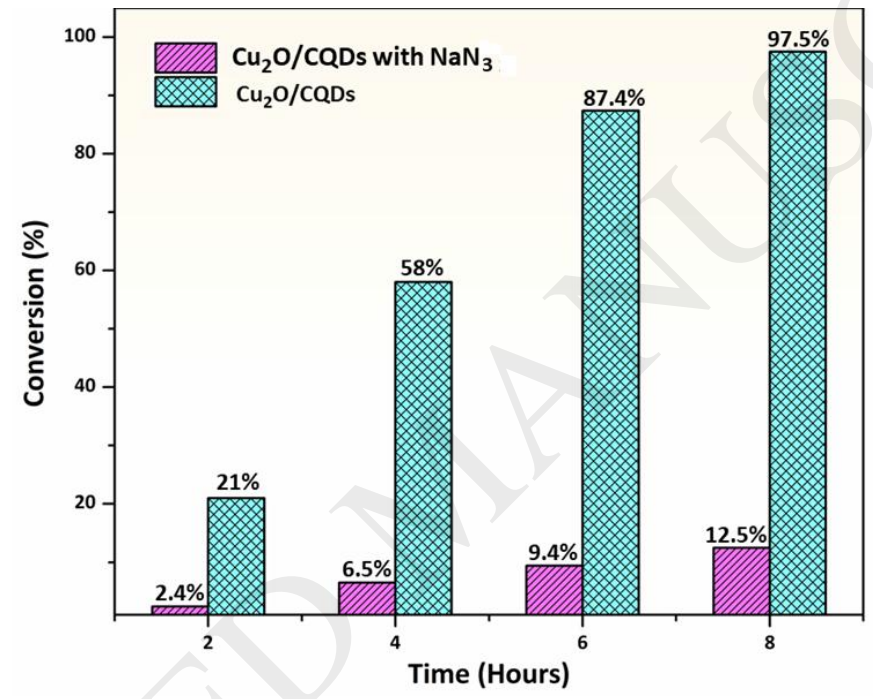

Figure 6. Conversion of benzylamine using $\mathrm{Cu}_{2} \mathrm{O} / \mathrm{CQD}$ photocatalyst with and without adding $\mathrm{NaN}_{3}$ as a quencher.

\subsection{Conclusions}

We have demonstrated an efficient, readily synthesized and cost effective photocatalyst i.e. heterostructured nanocomposite consisting of cuprous oxide and carbon quantum dots $\left(\mathrm{Cu}_{2} \mathrm{O} / \mathrm{CQD}\right)$ for the oxidative coupling of benzylamines using molecular oxygen as oxidant under visible light at ambient conditions. The developed nanocomposite $\mathrm{Cu}_{2} \mathrm{O} / \mathrm{CQD}$ exhibited superior activity as compared to bare $\mathrm{Cu}_{2} \mathrm{O}$ and $\mathrm{CQD}$. In addition, the nanocomposite showed 
excellent stability and efficient recyclability without any detectable leaching during the reaction. The superior performance of $\mathrm{Cu}_{2} \mathrm{O} / \mathrm{CQD}$ was mainly attributed to the enhanced charge transportation, effective separation of the photogenerated electron-hole pair and improved contact between photocatalyst and substrate molecules. Owing to the low cost and better efficiency, such $\mathrm{Cu}_{2} \mathrm{O} / \mathrm{CQD}$ nanocomposite can be used as a promising alternative to the noble metals (Au, Pd, Pt etc) in improving the photocatalytic ability of semiconductor photocatalysts.

\section{Acknowledgments}

Authors are thankful to Director IIP for granting permission to publish these results. AK is thankful to CSIR, New Delhi, for providing research fellowships. The CNRS, the University of Lille and the Hauts-de-France region are acknowledged for financial support. 


\section{References}

[1]. T. P. Yoon, M. A. Ischay, J. Du, Visible light photocatalysis as a greener approach to photochemical synthesis, Nature Chem. 2010 (2) 527-532.

[2]. X. Lang, X. Chen, J. Zhao, Heterogeneous visible light photocatalysis for selective organic transformations, Chem. Soc. Rev. 2014 (43) 473-486.

[3]. T. Zhang, W. Lin, Metal-organic frameworks for artificial photosynthesis and photocatalysis, Chem. Soc. Rev. 2014 (43) 5982-5993.

[4]. L. Huang, F. Peng, H. Yu, H. Wang, Preparation of cuprous oxides with different sizes and their behaviours of adsorption, visible-light driven photocatalysis and photocorrosion, Solid State Science 2009 (11) 129-138.

[5]. J. C. Wang, L. Zhang, W. X. Fang, J. Ren, Y. Y. Li, H. C. Yao, J. S. Wang, Z. J. Li, Enhanced Photoreduction $\mathrm{CO}_{2}$ Activity over Direct Z-Scheme $\alpha-\mathrm{Fe}_{2} \mathrm{O}_{3} / \mathrm{Cu}_{2} \mathrm{O}$ Heterostructures under Visible Light Irradiation, ACS Appl. Mater. Interfaces, 2015 (7) 8631-8639.

[6]. J. Zhang, H. Zhu, S. Zheng, F. Pan, T. Wang, $\mathrm{TiO}_{2}$ Film/ $/ \mathrm{Cu}_{2} \mathrm{O}$ microgrid heterojunction with photocatalytic activity under solar light irradiation, ACS Appl. Mater. Interfaces 2009 (1) 2111-2114.

[7]. Y. Wang, Y. Zhang, G. Zhao, H. Tian, H. Shi, T. Zhou, Design of a Novel $\mathrm{Cu}_{2} \mathrm{O} / \mathrm{TiO}_{2} /$ Carbon Aerogel Electrode and its Efficient Electrosorption-assisted visible light photocatalytic degradation of 2,4,6-trichlorophenol, ACS Appl. Mater. Interfaces 2012 (4) 3965-3972.

[8]. H. Li, Z. Kang, Y. Liu, S. T. Lee, Carbon nanodots: synthesis, properties and applications, J. Mater. Chem. 2012 (22) 24230-24253. 
[9]. H. Maaoui, P. Kumar, A. Kumar, G. H. Pan, R. Chtourou, S. Szunerits, R. Boukherroub, S. L. Jain, A Prussian blue/carbon dot nanocomposite as an efficient visible light active photocatalyst for C-H activation of amines, Photochem. Photobiol. Sci. 2016 (15) 12821288.

[10]. S. Dong, J. Feng, M. Fan, Y. Pi, L. Hu, X. Han, M. Liu, J. Sun, J. Sun, Recent developments in heterogeneous photocatalytic water treatment using visible lightresponsive photocatalysts: a review, RSC Adv. 2015 (5) 14610-14630.

[11]. Y. Zhang, N. Zhang, Z. R. Tang, Y. J. Xu, Transforming CdS into an efficient visible light photocatalyst for selective oxidation of saturated primary $\mathrm{C}-\mathrm{H}$ bonds under ambient conditions, Chem. Sci. 2012 (3) 2812-2822.

[12]. E. Zhang, H. Tian, S. Xu, X. Yu, Q. Xu, Iron-catalyzed direct synthesis of imines from amines or alcohol and amines via aerobic oxidative reactions under air, Org. Lett. 2013 (15) 2704-2707.

[13]. J. Gomez, G. G. Herbosa, J. V. Cuecas, A. Arnaiz, A. Carbayo, A. Munoz, L. Falvello, P. E. Fanwick, Diastereospecific and Diastereoselective synthesis of Ruthenium(II) complexes using N, N'-bidentate ligands aryl-pyridin-2-ylmethyl-amine $\mathrm{ArNH}-\mathrm{CH}_{2}-2$ $\mathrm{C}_{5} \mathrm{H}_{4} \mathrm{~N}$ and their oxidation to imine ligands, Inorg. Chem. 2006 (45) 2483-2493.

[14]. F. Su, S. C. Mathew, L. Mohlmann, M. Antonietti, X. Wang, S. Blechert, Aerobic Oxidative coupling of amines by carbon nitride photocatalysis with visible light, Angew. Chem. Int. Ed. 2011 (50) 657-660.

[15]. S. Furukawa, Y. Ohno, T. Shishido, K. Teramura, T. Tanaka, Selective amine oxidation using $\mathrm{Nb}_{2} \mathrm{O}_{5}$ photocatalyst and $\mathrm{O}_{2}$, ACS Catal. 2011 (1) 1150-1153.

[16]. A. Berlicka, B. Konig, Porphycene-mediated photooxidation of benzylamines by visible light, Photochem. Photobiol. Sci. 2010 (9) 1359-1366. 
[17]. F. Raza, J. H. Park, H. R. Lee, H. I. Kim, S. J. Jeon, J. H. Kim, Visible-light-driven oxidative coupling reactions of amines by photoactive $\mathrm{WS}_{2}$ nanosheets, ACS Catal. 2016 (6) 2754-2759.

[18]. A. Kumar, P. Kumar, C. Joshi, S. Ponnada, A. K. Pathak, A. Ali, B. Sheedhar, S. L. Jain, A $\left[\mathrm{Fe}(\text { bpy })_{3}\right]^{2+}$ grafted graphitic carbon nitride hybrid for visible light assisted oxidative coupling of benzylamines under mild reaction conditions, Green Chem. 2016 (18) 2514-2521.

[19]. H. Maaoui, F. Teodoresu, G. H. Pan, A. Addad, R. Chtourou, S. Szunerits, R. Boukherroub, Non-Enzymatic Glucose Sensing Using Carbon Quantum Dots Decorated with Copper Oxide Nanoparticles, Sensors 2016 (16) 1720.

[20]. X. An, K. Li, J. Tang, $\mathrm{Cu}_{2} \mathrm{O} /$ Reduced graphene oxide composites for the photocatalytic conversion of $\mathrm{CO}_{2}$, ChemSusChem 2014 (7) 1086-1093.

[21]. X. Zhou, H. Nie, Z. Yao, Y. Dong, Z. Yang, S. Huang, Facile synthesis of nanospindlelike $\mathrm{Cu}_{2} \mathrm{O}$ /straight multi-walled carbon nanotube hybrid nanostructures and their application in enzyme free glucose sensing, Sens. Actuators B 2012 (168) 1-7.

[22]. Y. Li, Y. Zhong, Y. Zhang, W. Weng, S. Li, Carbon quantum dots/octahedral $\mathrm{Cu}_{2} \mathrm{O}$ nanocomposites for non-enzymatic glucose and hydrogen peroxide amperometric sensor, Sens. Actuators B 2015 (206) 735-743. 


\section{Graphical Abstract}

Visible light assisted oxidative coupling of benzylamines using heterostructured nanocomposite photocatalyst

Anurag Kumar, Abderrahmane Hamdi, Yannick Coffinier, Ahmed Addad, Pascal Roussel, Rabah

Boukherrroub and Suman L. Jain

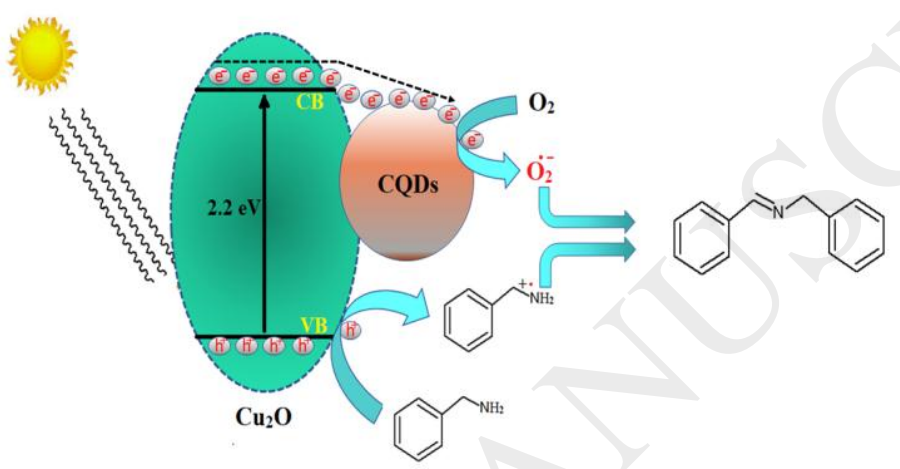

